\title{
IMPLEMENTASI METODE BACKPROPAGATION UNTUK PREDIKSI HARGA JUAL KELAPA SAWIT BERDASARKAN KUALITAS BUAH
}

\author{
Suci Andriyani ${ }^{1}$, \& Norenta Sitohang ${ }^{1}$ \\ ${ }^{1}$ Sistem Informasi, STMIK Royal \\ email: suciandriyani94@gmail.com
}

\begin{abstract}
Palm oil is a major flagship commodities Indonesia, plant products, crude palm oil has a high economic value so that it became one of the country's largest foreign exchange as compared to other plantation commodities. In the process of selling palm oil price prediction, data in the form of necessary factors which affect the selling price itself so in get predictions for the future. The prediction method used in this system is a method of Backpropagation Neural Network is a very good method in the process of pattern recognition considering his ability to adapt to the conditions of the network with the data provided by the learning process. The result of the method of Backpropagation form prediction price selling price of palm oil for the time to come.
\end{abstract}

Keywords: Neural Network, Backpropagation, Palm Oil

\begin{abstract}
Abstrak: Kelapa sawit merupakan komoditas unggulan utama Indonesia, tanaman yang produk utamanya yaitu sawit mentah ini memiliki nilai ekonomis tinggi sehingga menjadi salah satu devisa negara yang terbesar dibandingkan dengan komoditas perkebunan lainnya. Dalam proses prediksi harga jual kelapa sawit, diperlukan data berupa faktor-faktor yang mempengaruhi harga jual itu sendiri sehingga di peroleh prediksi untuk waktu yang akan datang. Metode prediksi yang digunakan dalam system ini adalah metode Jaringan Syaraf Tiruan Backpropagation merupakan metode yang sangat baik dalam proses pengenalan pola mengingat kemampuannya dalam mengadaptasikan kondisi jaringan dengan data yang diberikan dengan proses pembelajaran. Hasil dari metode Backpropagation berupa prediksi harga harga jual kelapa sawit untuk waktu yang akan datang.
\end{abstract}

Kata kunci: Jaringan Syaraf Tiruan, Backpropagation, Kelapa Sawit.

\section{PENDAHULUAN}

Kelapa sawit adalah tumbuhan industri/ perkebunan yang berguna sebagai penghasil minyak masak, minyak industri, maupun bahan bakar (Lina Arlina Nur Kadim, 2014: 49). Perkebunan kelapa sawit dapat menghasilkan keuntungan besar sehingga banyak hutan dan perkebunan lama dikonversikan menjadi perkebunan kelapa sawit. Penyebaran kelapa sawit di Indonesia berada pada pulau Sumatera, Kalimantan, Jawa, Sulawesi, Papua, dan beberapa pulau tertentu di Indonesia. Buah 
kelapa sawit digunakan sebagai bahan mentah minyak goreng, margarine, sabun, kosmetik, dan industri farmasi.

Sektor pertanian merupakan sektor yang sangat penting peranannya. Indonesia sebagai negara yang banyak mempunyai perkebunan kelapa sawit sehingga banyak persaingan investor di dunia pasar, yang dapat dilihat tidak konstanya harga kelapa sawit/ harga kelapa sawit berubah-ubah sesuai dengan standard dan hukum Indonesia (Asni, 2005: 2).

Selama ini permasalahan terhadap harga jual kelapa sawit yang tidak menentu membuat sebagian pihak tidak mampu mengetahui harga jual di masa depan. Dengan Jaringan Syaraf Tiruan komputer difungsikan sebagai alat bantu yang dapat memprediksi harga jual kelapa sawit tersebut.

Jaringan Syaraf Tiruan merupakan sistem pemrosesan informasi yang memiliki kemampuan pembelajaran terhadap data dan informasi yang diterima, kemampuan untuk memodelkan fungsi linear, komputasi paralel dan mempunyai sifat mentolerir ketidakpastian (fault tolerance). Penerapan Jaringan Syaraf Tiruan sangatlah luas, diantaranya adalah analisa dan perancangan Jaringan Syaraf Tiruan dengan metode Backpropagation pada aplikasi pengenalan tanda tangan (Wilis dkk, 2013). JST digunakan untuk mempediksi curah hujan (Naik et al, 2013). JST juga digunakan untuk peramalan jumlah penderita penyakit menggunakan Backpropagation (Aeri Rachmad et al, 2016).

Jaringan Syaraf Tiruan memberikan alat untuk membantu dokter untuk menganalisis model. Data klinis yang kompleks di berbagai aplikasi medis Sebuah Jaringan Syaraf Tiruan memiliki kemampuan untuk meniru jenis ini proses pengambilan keputusan dan menggunakan basis pengetahuan informasi sehingga diperlukan untuk mendiagnosa penyakit (Arti dan Maneesh, 2011).

Jaringan Syaraf Tiruan telah banyak diterapkan untuk membantu menyelesaikan berbagai macam permasalahan. Di antaranya Menggunakan Jaringan Syaraf Tiruan Backpropagation untuk seleksi penerimaan mahasiswa baru pada jurusan teknik komputer di Politeknik Negeri Sriwijaya (Mario dan Toni, 2013).

Dengan menggunakan Jaringan Syaraf Tiruan Backpropagation ini diharapkan dapat memberikan alternatif lain dalam memperkirakan dan memprediksi tingkat pertumbuhan penduduk di Kota Bengkulu pada setiap tahunnya (Aji Sudarjono, 2016). Selain itu penerapan Jaringan Syaraf Tiruan juga digunakan untuk Peramalan jumlah permintaan produksi (Mira dkk, 2013) dan digunakan juga Pada penelitian prediksi cuaca dengan menggunakan Jaringan Syaraf Tiruan. Secara sederhana Jaringan Syaraf Tiruan adalah sebuah alat pemodelan data statistik non-linier yang dapat digunakan untuk memodelkan hubungan yang kompleks antara input dan output untuk menemukan pola-pola pada data (Samuel dkk,2015).

\section{Jaringan Syaraf Tiruan}

Menurut Jong Jek Siang (2005), Jaringan Syaraf Tiruan adalah sistem pemrosesan informasi yang memiliki karakteristik mirip dengan Jaringan Syaraf Biologi. Jaringan Syaraf Tiruan dibentuk sebagai generalisasi model matematika dari jaringan syaraf biologi, dengan asumsi bahwa :

1. Pemrosesan informasi terjadi pada banyak elemen sederhana (neuron)

2. Sinyal dikirimkan diantara neuronneuron melalui penghubung-penghubung

3. Penghubung antar neuron memiliki bobot yang akan memperkuat atau memperlemah sinyal

4. Untuk menentukan output, setiap neuron menggunakan fungsi aktivasi (biasanya bukan fungsi linier) yang dikenakan pada jumlahan input yang diterima. Besarnya output ini 
selanjutnya dibandingkan dengan suatu batas ambang (threshold)

Jaringan Syaraf Tiruan dikarakteriskan oleh 3 hal berikut:

1. Pola hubungan antar neuron (disebut arsitektur jaringan)

2. Metode untuk menentukan bobot penghubung (disebut metode training/ learning/algoritma)

3. Fungsi aktivasi.

\section{Algoritma Backpropagation}

Ada dasarnya, pelatihan dengan metode backpropagation terdiri atas tiga langkah, yaitu sebagai berikut :

a. Data dimasukan ke input jaringan (feedforward)

b. Perhitungan dan propagasi balik dari error yang bersangkutan

c. Pembaharuan (adjustment) bobot dan bias

Saat umpan maju (feedforward), setiap unit input $\left(X_{i}\right)$ akan menerima sinyal input dan akan menyebabkan sinyal tersebut pada tiap hidden unit $\left(\mathrm{Z}_{\mathrm{j}}\right)$. Setiap hiden unit kemudian akan menghitung aktivasinya dan menerima sinyal $\left(\mathrm{Z}_{\mathrm{j}}\right)$. Kemudian, setiap unit output $\left(\mathrm{Y}_{\mathrm{k}}\right)$ juga akan menghitung aktivasinya $\left(\mathrm{Y}_{\mathrm{k}}\right)$ untuk menghasilkan respon terhadap input yang diberikan jaringan.

Saat proses pelatihan (training), setiap unit output membandingkan aktivasinya $\left(\mathrm{Y}_{\mathrm{k}}\right)$ dengan nilai target (desired output) untuk menentukan besarnya error. Berdasarkan error tersebut, dihitung faktor $\delta_{\mathrm{k}}$. Faktor $\delta_{\mathrm{k}}$ digunakan untuk mendistribusikan error dari output kembali ke layar sebelumnya. Dengan cara yang sama faktor $\delta_{\mathrm{j}}$ juga dihitung pada hidden unit $\mathrm{Z}_{\mathrm{j}}$. Faktor $\delta_{\mathrm{k}}$ digunakan untuk memperbaharui bobot antara hidden layer dan input layer.

Setelah semua faktor $\delta$ ditentukan, bobot untuk semua layer di adjust secara bersamaan. Pembaharuan bobot $\mathrm{W}_{\mathrm{jk}}$ (dari hidden unit $\mathrm{Z}_{\mathrm{j}}$ ke unit output $\mathrm{Y}_{\mathrm{k}}$ ) dilakukan berdasarkan faktor $\delta_{\mathrm{k}}$ dan aktivasi $\mathrm{Z}_{\mathrm{j}}$ dari hiden unit $Z_{j}$. Sedangkan pembaharuan bobot $\mathrm{V}_{\mathrm{ij}}$ (dari input $\mathrm{X}_{\mathrm{i}}$ ke hidden $\mathrm{Z}_{\mathrm{j}}$ ) dilakukan berdasarkan faktor $\delta_{\mathrm{j}}$ dan aktivasi $\mathrm{X}_{\mathrm{i}}$ dari input.

\section{METODOLOGI}

Pada Algoritma Backpropagation ini pelatihan untuk jaringan dengan satu layer tersembunyi (dengan fungsi aktivasi sigmoid biner) adalah sebagai berikut :

Langkah 0: Inisialisasi semua bobot dengan bilangan acak kecil.

$$
X^{\prime}=\frac{0.8(x-a)}{b-a}+0.1
$$

Langkah 1: Jika kondisi penghentian belum terpenuhi, lakukan langkah 2-9.

Langkah 2: Untuk setiap pasangan data pelatihan, lakukan langkah 3-8.

Fase I: Propagasi maju

Langkah 3: Tiap unit masukan menerima sinyal dan meneruskannya ke unit tersembunyi di atasnya.

Langkah 4: Hitung semua keluaran di unit tersembunyi $\quad z_{j} \quad(\mathrm{j}=1,2, \ldots, \mathrm{p})$.

$z_{-}$net $_{j}=v_{j \circ}+\sum_{i=1}^{n} x_{i} v_{j i}$

$z_{j}=f\left(z_{\text {net }_{j}}\right)=\frac{1}{1+e^{-z_{-} \text {net }_{j}}}$

Langkah 5: Hitung semua keluaran jaringan di unit keluaran $y_{k}(\mathrm{k}=1,2, .$. , $\mathrm{m})$.

$$
\begin{aligned}
& y_{-} \text {net }_{k}=w_{k o}+\sum_{j=1}^{p} z_{j} w_{k j} \\
& y_{k}=f\left(y_{-} \text {net }_{k}\right)=\frac{1}{1+e^{-y_{-} \text {net }_{k}}}
\end{aligned}
$$

Fase II: Propagasi mundur

Langkah 6: Hitung faktor kesalahan $\delta$ unit keluaran berdasarkan kesalahan di setiap unit keluaran $y_{k}(\mathrm{k}=1,2, . ., \mathrm{m})$.

$$
\begin{aligned}
& \delta_{k}=\left(t_{k}-y_{k}\right) f^{\prime}\left(y_{-} \text {net }_{k}\right)=\left(t_{k}-y_{k}\right) y_{k}\left(1-y_{k}\right) \\
& \delta_{k} \text { merupakan unit kesalahan yang } \\
& \text { akan dipakai dalam } \text { perubahan } \\
& \text { bobot lapisan di bawahnya } \\
&(\text { langkah7) }
\end{aligned}
$$


Hitung suku perubahan bobot wkj (yang akan dipakai nanti untuk merubah bobot $w_{k j}$ ) dengan laju percepatan $\alpha$.

$$
\begin{aligned}
& \Delta w_{k j}=\alpha \delta_{k} z_{j} \\
& \mathrm{k}=1,2, \ldots, \mathrm{m} ; \mathrm{j}=0,1, \ldots, \mathrm{p}
\end{aligned}
$$

Langkah 7: Hitung faktor kesalahan $\delta$ unit tersembunyi berdasarkan kesalahan di setiap unit tersembunyi $z_{j}(\mathrm{j}=1,2, \ldots, \mathrm{p})$.

$\delta_{-}$net $t_{j}=\sum_{k=1}^{m} \delta_{k} w_{k j}$

Faktor $\delta$ unit tersembunyi :

$\delta_{j}=\delta_{-}$net $_{j} f^{\prime}\left(z_{-}\right.$net $\left._{j}\right)=\delta_{-}$net $_{j} z_{j}\left(1-z_{j}\right)$

Hitung suku perubahan bobot $v_{j i}$ (yang akan dipakai nanti untuk merubah bobot $\left.v_{j i}\right)$

$$
\begin{gathered}
\Delta v_{j i}=\alpha \delta_{j} x_{i} \\
\mathrm{j}=1,2, \ldots, \mathrm{p} \quad ; \mathrm{i}=0,1, \ldots, \mathrm{n}
\end{gathered}
$$

Fase III : Perubahan bobot

Langkah 8: Hitung semua perubahan bobot perubahan bobot garis yang menuju ke unit tersembunyi :

$$
v_{j i}(\text { baru })=v_{j i}(\operatorname{lama})+\Delta v_{j i}
$$$$
(\mathrm{j}=1,2, \ldots, \mathrm{p} ; \mathrm{i}=0,1, \ldots, \mathrm{n})
$$

Perubahan bobot garis yang menuju ke unit keluaran:

$$
\begin{aligned}
& w_{k j}(\text { baru })=w_{k j}(\operatorname{lama})+\Delta w_{k j} \\
& (\mathrm{k}=1,2, \ldots, \mathrm{m} ; \mathrm{j}=0,1, \ldots, \mathrm{p}) \\
& \text { pada penelitian ini yaitu analisis } \\
& \text { penentuan harga jual kelapa sawit } \\
& \text { berdasarkan kualitas buah berdasarkan data } \\
& \text { dinas perkebunan pasaman barat Januari } \\
& \text { sampai Desember 2017. }
\end{aligned}
$$

\section{HASIL DAN PEMBAHASAN}

\section{Analisis Harga Jual Kelapa Sawit}

Kelapa sawit merupakan salah satu sektor industri yang sangat penting di Indonesia. Untuk dapat melakukan prediksi harga jual kelapa sawit itu sendiri, penulis mencoba untuk melakukan pengolahan beberapa data yang mempengaruhi harga kelapa sawit itu sendiri. Berikut yang

\begin{tabular}{|c|c|c|c|c|c|c|c|c|c|c|c|}
\hline No & Tahun & Bulan & Umur & $\begin{array}{l}\text { faktor } \\
\text { "k" }\end{array}$ & Harga & Rendemen & Harga TBS & Harga & Rendemen & $\begin{array}{c}\text { Harga } \\
\text { TBS }\end{array}$ & $\begin{array}{c}\text { Harga } \\
\text { TBS } \\
\end{array}$ \\
\hline & & & Tanaman & & $\mathrm{CPO}$ & $\mathrm{CPO}$ & $\mathrm{CPO}$ & Kernel & Kernel & Kernel & Akhir \\
\hline 1 & 2017 & Januari & 10 tahun $\mathrm{s} / \mathrm{d}$ & 86,24 & 6359,09 & 21,8 & 1199 & 4359,56 & 5,95 & 224,45 & 1423,27 \\
\hline 2 & & Februari & 20 Tahun & 86,24 & 6198,7 & 21,82 & 1169 & 4687,27 & 5,96 & 241,33 & 1409,91 \\
\hline 3 & & Maret & & 87,3 & 6790 & 21,84 & 1296 & 5200,45 & 5,97 & 271,04 & 1566,83 \\
\hline 4 & & April & & 87,99 & 7244,21 & 21,86 & 1393 & 5678,85 & 5,81 & 298,31 & 1691,71 \\
\hline 5 & & Mei & & 90 & 8460,34 & 21,88 & 1664 & 6835 & 5,83 & 367,24 & 2031,73 \\
\hline 6 & & Juni & & 90 & 8132 & 21,89 & 1600 & 6439,97 & 5,85 & 346,02 & 1945,91 \\
\hline 7 & & Juli & & 90 & 7396,3 & 21,83 & 1455 & 6971,33 & 5,86 & 347,57 & 1829,71 \\
\hline 8 & & Agustus & & 90 & 7196,07 & 21,81 & 1416 & 6776,8 & 5,93 & 363,12 & 1779,87 \\
\hline 9 & & September & & 90 & 7556,4 & 21,79 & 1487 & 7004,36 & 5,91 & 376,34 & 1862,99 \\
\hline 10 & & Oktober & & 90 & 8075,12 & 21,75 & 1589 & 6408,72 & 5,92 & 344,34 & 1933,04 \\
\hline 11 & & November & & 90 & 7858,4 & 21,79 & 1546 & 6564,53 & 5,84 & 352,71 & 1989,77 \\
\hline 12 & & Desember & & 90 & 8460,34 & 21,86 & 1700 & 6835 & 5,87 & 400,01 & 2100,01 \\
\hline
\end{tabular}
merupakan variabel-variabel yang akan digunakan dalam memprediksi harga kelapa sawit
1. Faktor "k"
2. Harga CPO
3. Rendemen $\mathrm{CPO}$
4. Harga TBS CPO
5. Harga Kernel
6. Rendemen Kernel
7. Harga TBS

Tabel 1. Data Harga TBS Januari-Desember 2017 
Data-data tersebut dinormalisasi dalam interval $[0,1]$ karena data yang digunakan bernilai positif.Selain itu juga terkait fungsi aktivasi yang diberikan yaitu sigmoid biner. Fungsi sigmoid adalah fungsi asimtotik (tidak pernah mencapai 0 ataupun 1), maka transformasi data dilakukan pada interval yang lebih kecil yaitu [0.1; 0.8], ditunjukkan dengan persamaan .

Keterangan :

$$
X^{\prime}=\frac{0.8(x-a)}{b-a}+0.1
$$

$0.8=$ Ketetapan

$\mathrm{x}=$ Nilai data $\mathrm{ke}-\mathrm{n}$

$\mathrm{a}=$ Nilai data terendah (data terendah

dari setiap input)

$\mathrm{b}=$ Nilai data tertinggi (data tertinggi dari setiap input)

Berikut merupakan contoh cara perhitungan transformasi data dengan sampel bulan Januari pada setiap variabel :

1. Variabel Faktor " $k$ " (X1)

$\mathrm{X} 1.1=(0,8 *(86,24-86,24) /(90-$ $86,24))+0,1=0,1$

2. Variabel Harga $\mathrm{CPO}$

$\mathrm{X} 2.1=(0,8 *(6198,7-$

$6198,7) /(8460,34-6198,7))+0,1=$ 0,156734

3. Variabel Rendemen CPO
$\mathrm{X} 3.1=(0,8 *(21.75-21.75) /(21.89-$

$21.75))+0,1=0,38571429$

4. Variabel Harga TBS CPO

$\mathrm{X} 4.1=(0,8 *(1169-1169) /(1700$ -

1169) $+0,1=0,145198$

5. Variabel Harga Kernel

$\mathrm{X} 5.1=(0,8 *(4359,56-$

$4359,56) /(7004,36-4359,56))+0,1=$ 0,1

6. Variabel Rendemen Kernel

X6.1 $=(0,8 *(5,81-5,81) /(5,97$ -

$5,81))+0,1=0,8$

7. Harga TBS Kernel

$\mathrm{X} 7.1=(0,8 *(224,45$ -

$224,45) /(400,01-224,45))+0,1=0,1$

8. Variabel Harga TBS Akhir (Target)

$\mathrm{T} 1=(0,8 *(1409,91-$

$1409,91) /(2100,01-1409,91))+0,1=$ 0,1

9. Harga TBS Kernel

$\mathrm{X} 7.1=(0,8 *(224,45-$

$224,45) /(400,01-224,45))+0,1=0,1$

10. Variabel Harga TBS Akhir (Target) $\mathrm{T} 1=(0,8 *(1409,91-$ $1409,91) /(2100,01-1409,91))+0,1=$ 0,1

Tabel 2. Hasil Transformasi Pola Penyusunan Pelatihan Data

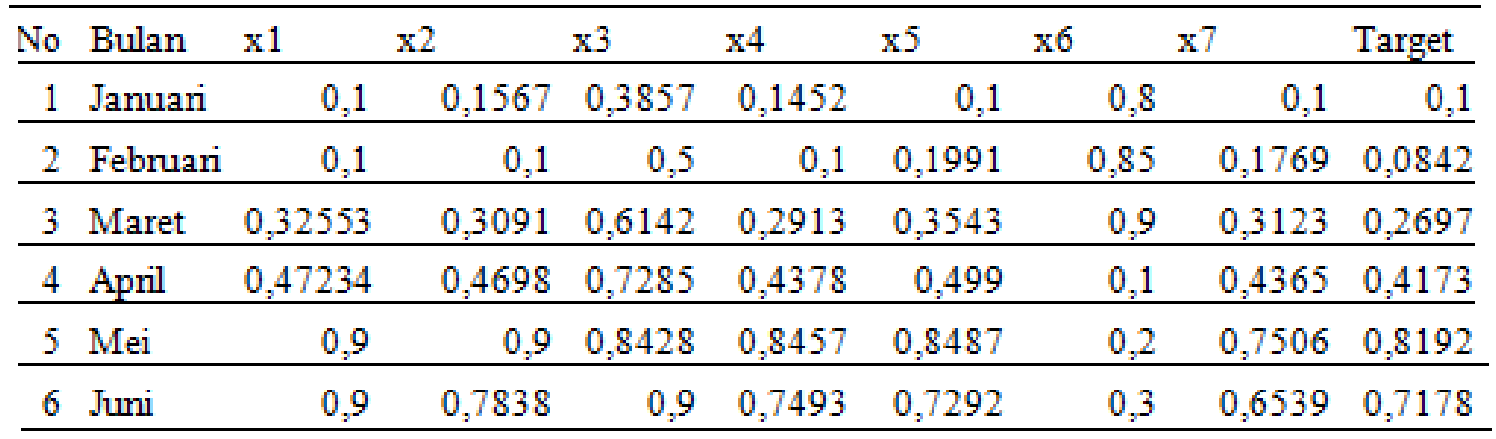


Available online at http://jurnal.stmikroyal.ac.id/index.php/jurteksi

Tabel 3. Hasil Transformasi pola penyusunan pengujian data

\begin{tabular}{|c|c|c|c|c|c|c|c|c|}
\hline No Bulan & $\mathrm{x} 1$ & $\mathrm{x} 2$ & $\mathrm{x} 3$ & $\mathrm{x} 4$ & $\mathrm{x} 5$ & $\mathrm{x} 6$ & $\mathrm{x} 7$ & Target \\
\hline $1 \mathrm{Juli}$ & 0,9 & 0,5236 & 0,5571 & 0,5308 & 0,89 & 0,35 & 0,661 & 0,5804 \\
\hline 2 Agustus & 0,9 & 0,4527 & 0,4428 & 0,4721 & 0,8311 & 0,7 & 0,7364 & 0,5215 \\
\hline 3 September & 0,9 & 0,5802 & 0,3285 & 0,5791 & 0,9 & 0,6 & 0,7921 & 0,6198 \\
\hline 4 Oktober & 0,9 & 0,7637 & 0,1 & 0,7327 & 0,7198 & 0,65 & 0,6463 & 0,7026 \\
\hline 5 November & 0,9 & 0,687 & 0,3285 & 0,6679 & 0,7669 & 0,25 & 0,6844 & 0,6621 \\
\hline 6 Desember & 0.9 & 0,9 & 0,7285 & 0.9 & 0,8487 & 0,4 & 0,9 & 0,9 \\
\hline
\end{tabular}

Tabel 4. Variabel Input Layer

\begin{tabular}{cc}
\hline & Januari \\
\hline $\mathrm{x} 1$ & 0,1 \\
\hline $\mathrm{x} 2$ & 0,1567 \\
\hline $\mathrm{x} 3$ & 0,3857 \\
\hline $\mathrm{x} 4$ & 0,1452 \\
\hline $\mathrm{x} 5$ & 0,1 \\
\hline $\mathrm{x} 6$ & 0,8 \\
\hline $\mathrm{x} 7$ & 0,1 \\
\hline $\begin{array}{c}\text { Targe } \\
\mathrm{t}\end{array}$ & 0,1 \\
\hline
\end{tabular}

Tabel 5. Nilai Bobot dari Input Ke Hidden Layer Pola 7-7-1

\begin{tabular}{|c|c|c|c|c|c|c|c|}
\hline Bobot & $\mathrm{z} 1$ & $\mathrm{z} 2$ & $\mathrm{z} 3$ & $\mathrm{z} 4$ & $\mathrm{z} 5$ & $\mathrm{z} 6$ & $\mathrm{z} 7$ \\
\hline $\mathrm{v} 1$ & $-1,1727$ & 3,3843 & 9,8239 & $-1,3558$ & 3,3855 & 4,487 & 1,2013 \\
\hline v2 & 3,9342 & $-4,7475$ & $-3,9759$ & 2,5823 & 0,1874 & 3,1572 & 6,1593 \\
\hline v3 & 3,8598 & 5,3169 & 3,1777 & 4,7564 & 3,8787 & $-0,1975$ & 2,809 \\
\hline $\mathrm{v} 4$ & 4,9807 & 0,8208 & $-1,9943$ & $-1,6335$ & $-0,135$ & $-4,5707$ & 7,2829 \\
\hline v5 & 4,52 & 1,7281 & 2,5968 & $-1,0514$ & $-4,4002$ & 2,1616 & 7,4422 \\
\hline v6 & $-1,9584$ & $-3,933$ & 4,586 & 1,5038 & 3,1744 & $-1,9936$ & $-8,0319$ \\
\hline v7 & 1,7355 & 0,7008 & $-2,2977$ & 1,0131 & 7,4093 & $-5,1713$ & $-2,4674$ \\
\hline
\end{tabular}

Tabel 6. Nilai bobot dari Hidden Layer ke Output Pola 7-7-1

\begin{tabular}{cc}
\hline Bobot & Y \\
\hline W1 & 0,097 \\
\hline W2 & $-0,4756$ \\
\hline W3 & 0,1947 \\
\hline W4 & $-0,9014$ \\
\hline W5 & 0,1421 \\
\hline W6 & $-0,4017$ \\
\hline
\end{tabular}


Tabel 7. Nilai Bias dari Input ke Hidden Layer pola 7-7-1

\begin{tabular}{cc}
\hline Bias & $\mathrm{Vj}$ \\
\hline 1 & $-7,4432$ \\
\hline 2 & $-5,0107$ \\
\hline & - \\
3 & 13,0488 \\
\hline 4 & $-1,5946$ \\
\hline 5 & $-5,2226$ \\
\hline 6 & $-0,2712$ \\
\hline
\end{tabular}

Tabel 8. Nilai Bias dari Hidden Layer ke output Pola 7-7-1

\begin{tabular}{cc}
\hline Bias & 1 \\
\hline $\mathrm{Wj}$ & 0,501 \\
\hline
\end{tabular}

Hitung perubahan nilai bias dari unit tersembunyi ke output:

$W_{0(\text { bias baru })}=0.501+(-0.0613)=0.4396$

Tabel 9. Nilai Bias dari Hidden Layer ke Neuron Output

\begin{tabular}{cc}
\hline Bias & 1 \\
\hline $\mathrm{Wj} 1$ & 0,4396 \\
\hline
\end{tabular}

Setelah proses pelatihan selesai, data keluaran yang sudah didapatkan dari pelatihan jaringan adalah yang masih dalam bentuk normalisasi, sehingga mesti dilakukannya proses denormalisasi data yang bertujuan untuk mengembalikan nilai hasil keluaran data yang masih dalam bentuk normalisasi kedalam bentuk data yang sebenarnya, dengan persamaan :

$$
\begin{aligned}
X^{\prime} & =x\left(x_{\max }-x_{\min }\right)+x_{\min } \\
X^{\prime} & =0.1 *(2100.01-1409.91)+1409.91 \\
& =1478.92
\end{aligned}
$$

\section{Hasil Pelatihan dan Pengujian dengan MATLAB}

Untuk melakukan pelatihan dan pengujian hasil dari prediksi harga jual kelapa sawit, maka pengenalan pola tersebut juga akan diujikan ke dalam sistem komputerisasi. Pelatihan yang dilakukan dalam Matlab dapat menggunakan berbagai fungsi, tujuannya adalah mempercepat pelatihan.

Matlab menyediakan fungsi-fungsi khusus untuk menyelesaikan model Jaringan Syaraf Tiruan, pengguna hanya tinggal memasukan vektor masukan, target, model dan parameter yang diinginkan.

Jaringan Syaraf Tiruan dengan algoritma Backpropagation dibentuk dengan membuat generalisasi aturan pelatihan dan pengujian dalam model Windrow-Hooff dengan cara menambahkan lapisan tersembunyi. Standar metode Backpropagation menggunakan algoritma penurunan gradient.

Apabila kita telah selesai melakukan proses pelatihan data, maka selanjutnya akan dilakukan pula proses pengujian data dengan pola-pola arsitektur yang sama dengan pola pelatihan data yang telah dilakukan sebelumnya. Berikut data proses pengujian yang dapat dilihat pada tabel 3

Tabel 10. Hasil Transformasi pola penyusunan pengujian data

\begin{tabular}{cccccccccr}
\hline $\mathrm{N}$ & & & & & & & & & \\
$\mathrm{o}$ & Bulan & $\mathrm{x} 1$ & $\mathrm{x} 2$ & $\mathrm{x} 3$ & $\mathrm{x} 4$ & $\mathrm{x} 5$ & $\mathrm{x} 6$ & $\mathrm{x} 7$ & Target \\
\hline 1 & Juli & 0,9 & 0,5236 & 0,5571 & 0,5308 & 0,89 & 0,35 & 0,661 & 0,5804 \\
\hline 2 & Agustus & 0,9 & 0,4527 & 0,4428 & 0,4721 & 0,8311 & 0,7 & 0,7364 & 0,5215 \\
\hline 3 & September & 0,9 & 0,5802 & 0,3285 & 0,5791 & 0,9 & 0,6 & 0,7921 & 0,6198 \\
\hline 4 & Oktober & 0,9 & 0,7637 & 0,1 & 0,7327 & 0,7198 & 0,65 & 0,6463 & 0,7026 \\
\hline 5 & november & 0,9 & 0,687 & 0,3285 & 0,6679 & 0,7669 & 0,25 & 0,6844 & 0,6621 \\
\hline 6 & Desember & 0,9 & 0,9 & 0,7285 & 0,9 & 0,8487 & 0,4 & 0,9 & 0,9 \\
\hline
\end{tabular}


Tabel 11. Perbandingan Epoch dari Pola yang Diuji

\begin{tabular}{lrrrr}
\hline & $7-4-1$ & $7-5-1$ & \multicolumn{1}{c}{$7-6-1$} & \multicolumn{1}{c}{$7-7-1$} \\
\hline Epoch Pelatihan & 749 & 35 & 1591 & 1217 \\
\hline MSE Pengujian & 0,00099984 & 0,0017 & 0,00099733 & 0,0009998 \\
\hline Akurasi (100-MSE) & 99.9990002 & 99.99900016 & 99.99900267 & 99.9990002 \\
\hline
\end{tabular}

Tabel 12. Hasil Akhir perbandingan Data Aktual dan Data Jaringan Syaraf Tiruan

\begin{tabular}{rlrrrrr}
\hline & Bulan & \multicolumn{1}{l}{ Aktual } & \multicolumn{1}{l}{ JST } & \multicolumn{1}{l}{ (Selisih) } & \multicolumn{1}{l}{ Akurasi } & Error \\
\hline 1 & Januari & 1423,27 & 1436,2 & -13 & 100,91 & $-0,91$ \\
\hline 2 & Februari & 1409,91 & 1423,46 & -14 & 100,96 & $-0,96$ \\
\hline 3 & Maret & 1566,83 & 1581,78 & -15 & 100,95 & $-0,95$ \\
\hline 4 & April & 1691,71 & 1701,2 & -9 & 100,56 & $-0,56$ \\
\hline 5 & Mei & 2031,73 & 2033,03 & -1 & 100,06 & $-0,06$ \\
\hline 6 & Juni & 1945,91 & 1949,73 & -4 & 100,2 & $-0,2$ \\
\hline 7 & Juli & 1829,71 & 1830,1 & 0 & 100,02 & $-0,2$ \\
\hline 8 & Agustus & 1779,87 & 1780,51 & -1 & 100,04 & $-0,036$ \\
\hline 9 & September & 1862,99 & 1863,29 & 0 & 100,02 & $-0,02$ \\
\hline 10 & Oktober & 1933,04 & $19,32.02$ & 1 & 99,95 & 0,05 \\
\hline 11 & November & 1989,77 & 1898,16 & 1 & 99,97 & 0,03 \\
\hline 12 & Desember & 2100,01 & 2100,31 & 0 & 100,01 & $-0,01$ \\
\hline \multicolumn{2}{c}{ Total } & 21473,76 & 21529,8 & -56 & 1203,647 & $-3,6466$ \\
\hline Rata-rata & 1789,48 & 1794,15 & -5 & 100,3039 & $-0,3038833$ \\
\hline
\end{tabular}

Dari hasil beberapa pola yang digunakan dalam proses pengujian data Jaringan Syaraf Tiruan dengan Algoritma Backpropagation menggunakan Matlab, didapatkan kesimpulan bahwa model pola 7-6-1 epoch = 166 dan pencapaian MSE pada saat pengujian dengan MSE $=0.001$ dengan akurasi $99.99 \%$. Adapun data perbandingan dari masing-masing pola dapat dilihat pada tabel 11

\section{Perbandingan Hasil Prediksi Harga Jual Kelapa Sawit}

Setelah dilakukan proses pelatihan data dan pengujian data akan dilakukan perbandingan data beban puncak dengan hasil prediksi menggunakan Jaringan Syaraf Tiruan algoritma Backpropagation.

Berikut hasil dari perbandingan harga jual kelapa sawitp data aktual dan data prediksi dengan Jaringan Syaraf Tiruan algoritma Backpropagation dengan pola 77-1 yang dapat dilihat pada tabel 12 .

\section{SIMPULAN}

Berdasarkan analisa dan pengujian menggunakan Software Matlab pada data harga jual kelapa sawit, maka dapat diambil beberapa kesimpulan sebagai berikut :

1. AlgoritmaBackpropagation merupakan salah satu algoritma yang mudah diterapkan untuk menyelesaikan beberapa permasalahan terutama yang berkaitan dengan masalah prediksi.

2. Dengan learning rate, target error dan data pembelajaran yang sama belum pasti menghasilkan tingkat prediksi yang sama, hal ini dikarenakan nilai bobot-bobot pada tiap-tiap neuron yang dihasilkan oleh setiap pembe- 
lajaran berbeda. Penyebab bobot dari tiap-tiap neuron yang dihasillkan berbeda dikarenakan pemberian nilai bobot awal dilakukan dengan nilai random.

3. Metode Jaringan Syaraf Tiruan yang digunakan untuk memprediksi harga jual kelapa sawit adalah metode Backpropagation dengan pembagian data menjadi 2 bagian yaitu 6 data untuk pelatihan dan 6 data untuk pengujian diperoleh pola 7-6-1 sebagai arsitektur terbaik. Didapat hasil presentase akurasi data 99,99\%.

4. Selisih antara beban data aktual dengan beban hasil prediksi Jaringan Syaraf

\section{DAFTAR PUSTAKA}

Sudarsono, A. (2016). Jaringan Syaraf Tiruan Untuk Memprediksi Laju Pertumbuhan Penduduk Menggunakan Metode Bacpropagation (Studi Kasus Di Kota Bengkulu). Media Infotama, 12(1).

Gupta, A., \& Shreevastava, M. (2011). Medical diagnosis using back propagation algorithm. Int. J. Emerg. Technol. Adv. Eng, 1(1), 55-58.

Haryanto, S. A. F., Ernawati, E., \& Puspitaningrum, D. (2015). Implementasi Jaringan Syaraf Tiruan Backpropagation Untuk Memprediksi Cuaca (Studi Kasus: Kota Bengkulu). Rekursif: Jurnal Informatika, 3(2).

Kaswidjanti, W., Widiastuti, F., \& Rustamaji, H. (2013). Analisis Dan Perancangan Jaringan Saraf Tiruan Dengan Metode Backpropagation Pada Aplikasi Pengenalan Tanda Tangan. Jurnal Teknik, 3(2).
Tiruan dinyatakan dalam persentase atau persen error. Tingkat error terbesar terdapat pada data Dari data di atas dapat dilihat tingkat error terbesar terdapat pada data bulan Maret dengan selisih error sebesar -15 dengan persentase akurasi $100,95 \%$ dan persen error sebesar $-0,95 \%$ dan data bulan Februari dengan selisih error sebesar 14 dengan persentase akurasi 100,96\% dan persen error sebesar $-0,96 \%$. Hal ini terjadi karena hasil prediksi JST pada bulan Maret dan Februari melebihi target data aktualnya sehingga memiliki nilai error yang besar.
Lesnussa, Y. A., Latuconsina, S., \& Persulessy, E. R. (2015). Aplikasi Jaringan Saraf Tiruan Backpropagation untuk Memprediksi Prestasi Siswa SMA (Studi kasus: Prediksi Prestasi Siswa SMAN 4 Ambon). Jurnal Matematika Integratif, 11(2), 149-160.

Matondang, Z. A. (2013). Jaringan Syaraf Tiruan Dengan Algoritma Backpropagation Untuk Penentuan Kelulusan Sidang Skripsi. Pelita Informatika: Informasi dan Informatika, 4(1).

Puspitaningrum, Diyah. (2006). Pengantar Jaringan Syaraf Tiruan. Yogyakarta: Andi Offset.

Risnawati, R., \& Handayani, M. (2017). penerapan Jaringan Saraf Tiruan Untuk Proyeksi Logistik Berdasarkan Prediksi Pasien Menggunakan Algoritma Backpropagation. JURTEKSI, 4(1), 21-28. 
Available online at http://jurnal.stmikroyal.ac.id/index.php/jurteksi

Siang, Jong Jek. (2005). Jaringan Syaraf Tiruan dan Pemprogramannya
Menggunakan Matlab. Yogyakarta: Andi Offset. 